\title{
Mort programmée des cellules germinales testiculaires : causes et mécanismes mis en jeu
}

\author{
Souheila AMARA, Aline BOZEC, Mohamed BENAHMED, Claire MAUDUIT \\ INSERM U 407, Université Claude Bernard Lyon I, CHU, Hôpital Lyon Sud, \\ Service Anatomie Pathologique, Lyon
}

\section{RÉSUMÉ}

La spermatogenèse résulte d'un équilibre entre prolifération et apoptose. Si cet équilibre est rompu il peut conduire à certaines pathologies testiculaires : cancers testiculaires, infertilités. L'apoptose semble être particulièrement importante lors de la spermatogenèse puisque 60 à $75 \%$ des cellules germinales formées n'atteignent pas le stade spermatozoïde.

Dans les cellules germinales de rongeurs ou bien humaines, les différentes molécules de l'apoptose ont été détectées : caspases effectrices qui sont au cœur du processus et en amont les protéines de la voie des récepteurs de mort ou de la voie mitochondriale. Selon le type d'apoptose des cellules germinales (apoptose physiologique, induite par un retrait hormonal, par des lésions chimiques ou physiques), une ou les différentes voies entrent en jeu.

Enfin, dans différentes pathologies testiculaires humaines, les voies de l'apoptose et particulièrement les caspases semblent être impliquées.

Mots clés : spermatogenèse, apoptose, caspases, $\mathrm{Bc} / 2$, récepteurs de mort, infertilité masculine

\section{INTRODUCTION}

La spermatogenèse résulte d'un équilibre entre prolifération et apoptose précisément contrôlé dans le temps et dans l'espace, toutefois, les gènes régulant ces phénomènes sont encore très mal connus. L'équilibre entre la prolifération et l'apoptose peut être rompu et serait à l'origine de certaines pathologies testiculaires (cancer testiculaire, stérilité masculine). Le processus apoptotique (ou mort cellulaire programmée) semble être particulièrement important dans le cadre de la spermatogenèse. En effet, 60 à $75 \%$ des cellules germinales formées n'atteignent jamais le stade spermatozoïde et sont éliminées par apoptose. Dans ce contexte, la régulation de l'apoptose semble être un élément majeur pour le bon déroulement du processus spermatogénique et l'on peut penser qu'une dérégulation de la mort programmée des cellules germinales soit une étiologie possible des cancers testiculaires ou des stérilités masculines. Dans le cadre de cette revue, nous nous attacherons, après avoir défini les mécanismes apoptotiques, à décrire les différentes périodes et les mécanismes apoptotiques impliqués dans la spermatogenèse normale. Dans une seconde partie, nous indiquerons les voies apoptotiques impliquées selon le type d'induction de la mort programmée dans les modèles expérimentaux. Enfin, nous soulignerons quels sont les liens identifiés à l'heure actuelle entre l'apoptose et les pathologies testiculaires humaines.
Correspondance :

Dr Claire MAUDUIT - Laboratoire de Communication Cellulaire en Biologie de la Reproduction, Unité INSERM 407, Faculté de Médecine Lyon-Sud, BP12, 69921 Oullins Cedex France - Tel 04.78.86.31.24 -

Fax 04.78.86.31.16 - Email mauduit@grisn.univ-lyon1.fr 


\section{L'APOPTOSE : DÉFINITION ET MÉCANISMES D'ACTION}

\section{Définition}

L'apoptose est un processus spontané d'élimination cellulaire, permettant d'assurer le renouvellement cellulaire. La mort cellulaire apoptotique intervient ainsi dans le maintien de l'homéostasie cellulaire et tissulaire de façon opposée à la mitose. En effet, alors que les mitoses permettent la réplication cellulaire et l'hyperplasie tissulaire, l'apoptose conduit à la disparition des cellules et à l'hypoplasie tissulaire. Ainsi, grâce à l'apoptose, les cellules non souhaitées ou en surnombre sont éliminées, ceci dès l'embryogenèse. L'apoptose, indispensable au renouvellement permanent des tissus, peut néanmoins connaître des défaillances lors de sa régulation. Soit le mécanisme s'emballe et conduit alors à une dépopulation cellulaire progressive se traduisant par des pathologies dégénératives, par exemple dans le domaine neurologique tels que la maladie d'Alzheimer, ou de Parkinson ; soit le mécanisme est défaillant et l'on assiste à la survie et la multiplication anarchique de cellules devenues immortelles qui seront à l'origine de cancers. Ce même processus est également invoqué dans certaines maladies auto-immunes telle l'arthrite rhumatoïde.

L'apoptose présente des caractéristiques morphologiques et biochimiques spécifiques. Morphologiquement, l'apoptose correspond à une rétraction progressive de la cellule, avec condensation de la chromatine et du cytoplasme, suivie d'une fragmentation caractéristique de I'ADN aboutissant à la formation de fragments cellulaires ou corps apoptotiques. Les organites intracellulaires contenus dans les corps apoptotiques sont structurellement intacts et la formation de corps apoptotiques prévient le relargage des constituants intracellulaires et donc la réaction inflammatoire. Les corps apoptotiques formés sont ensuite phagocytés par les macrophages ou les cellules du voisinage. En ce sens, l'apoptose doit être distinguée de la nécrose qui aboutit à l'éclatement de la cellule suivi d'une réaction inflammatoire locale. Toutefois, la frontière entre apoptose et nécrose n'est pas hermétique puisqu'une cellule débutant un processus de mort cellulaire apoptotique peut finir en nécrose.

Le déroulement du processus apoptotique peut être divisé en trois phases: une phase d'initiation enclenchée par un stimulus dont le signal est transmis à l'intérieur de la cellule (transduction), une phase effectrice où la cellule s'engage vers un point de non retour et enfin une phase de dégradation des structures cellulaires. A cette dernière étape les caractéristiques morphologiques de l'apoptose deviennent évidentes (Figure 1).

\section{Phase d'initiation}

L'apoptose peut être induite par différents stimuli endogènes ou exogènes comme la déplétion en facteurs de croissance, en hormones (ex : glucocorticoïdes, testostérone), l'induction des récepteurs de mort, une hyperthermie, des agents physiques (radiations) ou chimiques (agents génotoxiques), des virus. La transduction des signaux apopto- tiques induits par ces différents stimuli se fait classiquement selon deux voies : la voie des récepteurs de mort et/ou la voie mitochondriale (Figure 1).

\section{a)Transduction du signal de mort par la voie des récep- teurs de mort}

Les récepteurs de mort appartiennent à la super famille des récepteurs du TNF (tumor necrosis factor). Les trois principaux systèmes de cette super famille sont : Fas, TNF, et TRAIL (Tableau 1). L'induction du signal de mort par ces trois systèmes est très semblable, le système Fas sera pris pour exemple. La fixation du ligand FasL à son récepteur Fas induit le regroupement de trimères Fas-FasL. L'association de Fas/FasL en micro-agrégats permet, dans la cellule, le recrutement puis la formation d'un complexe multi-protéique constitué de la protéine adaptatrice FADD (Fas-associated death domain) et de caspases initiatrices comme la procaspase-8. Cet ensemble Fas, FADD, procaspase-8 est appelé le complexe de signalisation de mort induite ou DISC (death inducing signaling complex). Dans ce complexe, la protéine adaptatrice FADD fait le lien entre le récepteur Fas via son domaine ( $D D$, Death Domain) et la procaspase-8 via son domaine DED (Death Effector Domain). Lors que le DISC est formé, la procaspase-8 se clive et ainsi s'autoactive [121]. La protéine ainsi libérée est de plus petite taille, c'est la caspase-8 activée qui est capable d'activer la phase effectrice de l'apoptose par clivage des caspases effectrices (voir plus loin). Actuellement il existe trois caspases initiatrices connues impliquées dans la voie des récepteurs de mort: les caspases 2,8 et 10 (Figure 2).

\section{b) Transduction du signal de mort par la voie mito- chondriale}

La mitochondrie est identifiée depuis longtemps comme l'organite indispensable à la production d'ATP cellulaire et de ce fait indispensable à la survie de la cellule. Différents stimuli engendrant un stress ou un dommage cellulaire, que ce soit à la suite d'un choc thermique, osmotique, de radiations ionisantes, d'un seuvrage en hormones ou en facteurs de croissance, induisent une perméabilisation des membranes mitochondriales accompagnée d'une dissipation de la différence de potentiel membranaire mitochondrial. Si les mécanismes précis de cette perméabilisation des membranes mitochondriales restent encore controversés, la perméabilisation est en soi à l'origine de la libération de protéines ou peptides apoptogènes situés dans l'espace entre les membranes interne et externe de la mitochondrie. La maîtrise de l'intégrité des membranes mitochondriales est le point central de la régulation de la voie mitochondriale. $\mathrm{Ce}$ rôle est dévolu a une famille de protéines : la famille $\mathrm{Bcl}_{2}$. Les différentes protéines de cette famille contiennent un ou plusieurs domaines $\mathrm{BH}(\mathrm{BCl}$ homology domain). Les membres contenant quatre domaines $\mathrm{BH}$ sont des protéines anti-apoptotiques ( $\mathrm{Bcl}_{2}, \mathrm{Bcl}-\mathrm{x} \mathrm{L}, \mathrm{Bcl}-\mathrm{w}, \mathrm{Mcl}-\mathrm{I}, \mathrm{A} 1$, Diva) ; les autres protéines sont pro-apoptotiques et contiennent soit trois domaines BH (Bax, Bak), soit un seul (Bid, Bad, Bim) $[1,24,128,140]$. Ces différents protéines interagissent entre elles formant des homodimères ou des hétérodimères 
Tableau 1 : les différents membres de la superfamille du TNF.

\begin{tabular}{lll}
\hline Récepteurs & Ligands & Références \\
\hline Fas (CD95/APO-1) & $\begin{array}{l}\text { FasL, sFasL (Ligand soluble } \\
\text { bloquant le récepteur) }\end{array}$ & {$[26,49,112]$} \\
$\begin{array}{l}\text { TNF-R1 } \\
\text { TNF-R2 }\end{array}$ & TNF $\alpha$, TNFß & {$[126]$} \\
$\begin{array}{l}\text { DR5, DR4 } \\
\text { (récepteurs induisant un signal de mort) }\end{array}$ & & \\
$\begin{array}{l}\text { DcR1, DcR2 } \\
\text { (récepteurs leurres, n'induisent pas de } \\
\text { signal de mort) }\end{array}$ & TRAIL & {$[14]$} \\
\hline
\end{tabular}

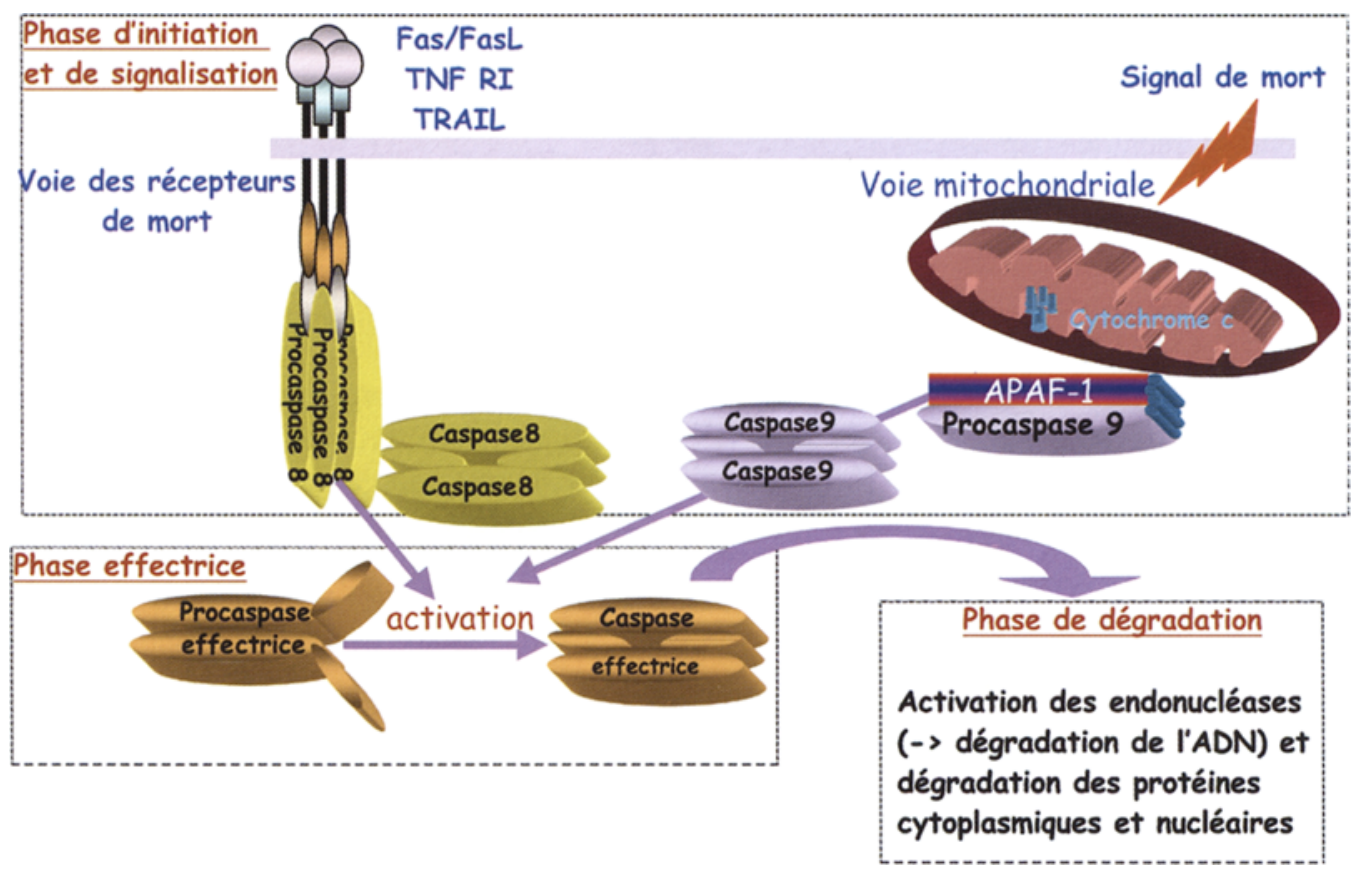

Figure 1 : Schéma général des différentes étapes de l'apoptose.

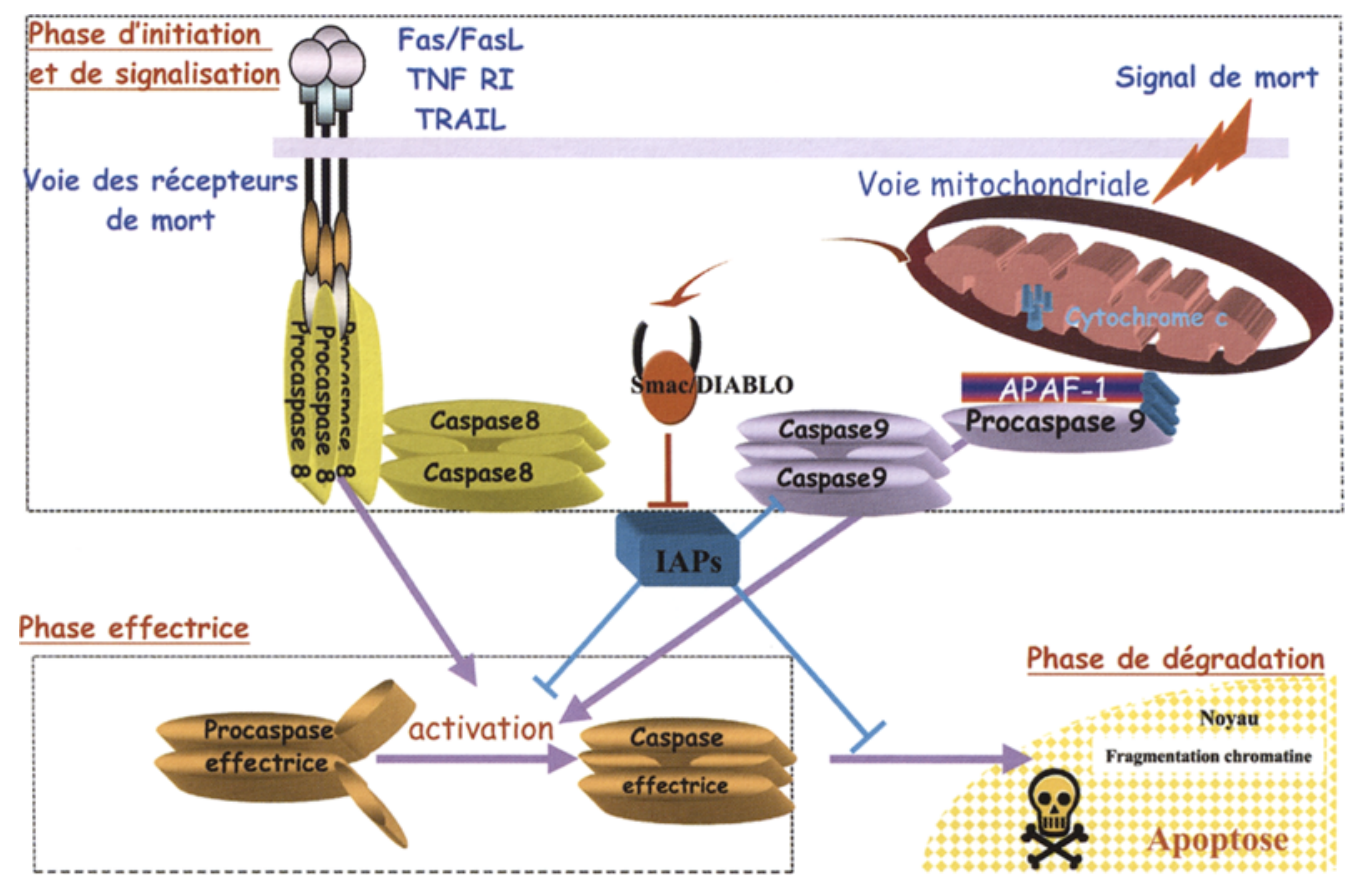

Figure 2 : Schéma d'activation de la voie des récepteurs de mort. 
$[24,128,140]$. La majorité des protéines de la famille $\mathrm{Bcl}_{2}$ ont une partie carboxy-terminale hydrophobe qui assure leur ancrage au niveau de la membrane externe mitochondriale, mais aussi des membranes du réticulum endoplasmique et du noyau. Les molécules anti-apoptotiques se localisent à l'état de repos, au niveau de la mitochondrie tandis que les protéines pro-apoptotiques se localisent au niveau du cytosol ou des microtubules. A la suite d'un signal apoptotique, ces dernières s'insèrent dans la membrane mitochondriale et induisent sa perméabilisation [17]. A partir des similarités structurales observées entre certaines toxines bactériennes et les protéines pro-apoptotiques, il a été suggéré que ces dernières forment des canaux ou des pores dans la membrane mitochondriale provoquant la libération de facteurs apoptogènes [96]. Les facteurs apoptogènes libérés nommés SIMP (soluble inter membrane mitochondrial proteins), sont essentiellement le cytochrome $c$ et la protéine Smac/DIABLO. Une fois libéré dans le cytoplasme, le cytochrome $c$ se fixe à une protéine adaptatrice (Apaf-1) qui recrute à son tour une caspase initiatrice la procaspase-9. Ces différentes molécules forment, en présence d'ATP, un complexe multiprotéique appelé l'apoptosome. La formation de l'apoptosome est à l'origine de l'activation de la procaspase-9 [145]. La caspase 9 activée est capable d'activer l'étape suivante : les caspases de la phase effectrice (Figure 3).

\section{Phase effectrice}

L'activation de la voie des récepteurs de mort ou de la voie mitochondriale provoque l'activation de caspases dites initiatrices (caspases-8, 10 ou 2 pour la voie des récepteurs de mort ; caspase-9 pour la voie mitochondriale). Les caspases initiatrices activées sont capables de cliver les procaspases effectrices $(3,6$ ou 7$)$ et ainsi de transmettre le signal apoptotique dans la cellule. Les caspases effectrices activées par les caspases initiatrices, clivent différents substrats cellulaires (protéines du cytosquelette) ou bien activent des endonucléases responsables de la fragmentation de l'ADN (Figure1).

L'activation et/ou l'activité des caspases effectrices est régulée par une famille de protéines : les IAPs (Inhibitors of Apoptosis Proteins). La famille des IAPs comprend actuellement neufs membres : XIAP, c-IAP1, c-IAP2, NAIP, MLIAP, ILP-2, Livin, Apollon et Survivine [15, 18, 21, 48, 88, 91]. Ces protéines possèdent toutes un ou plusieurs domaines BIR (Bacculovirus IAP repeat domain) capables de se lier aux caspases et d'inhiber soit leur activation soit leur activité. Un niveau supplémentaire de régulation de l'action des caspases existe, il est sous le contrôle d'une SIMP : Smac/DIABLO. Cette protéine se lie aux IAPs et les empêche d'inhiber les caspases. En somme, dans la cellule, l'exécution de la phase effectrice sera fonction (i) de l'existence d'un processus d'activation des procaspases effectrices et (ii) du rétro contrôle exercé par les IAPs et le Smac/DIABLO, ceci déterminant la quantité des caspases effectrices actives présente dans la cellule (Figure 4).

\section{Phase de dégradation}

C'est au cours de cette phase que les variations morphologiques et biochimiques sont mises en évidence, c'est-à-dire la fragmentation de l'ADN et la dégradation des protéines structurales. Ces modifications résultent de l'activité des caspases effectrices qui activent des enzymes directement impliquées dans la fragmentation de l'ADN comme la DFF (DNA Fragmentation Factor) ou qui dégradent les protéines

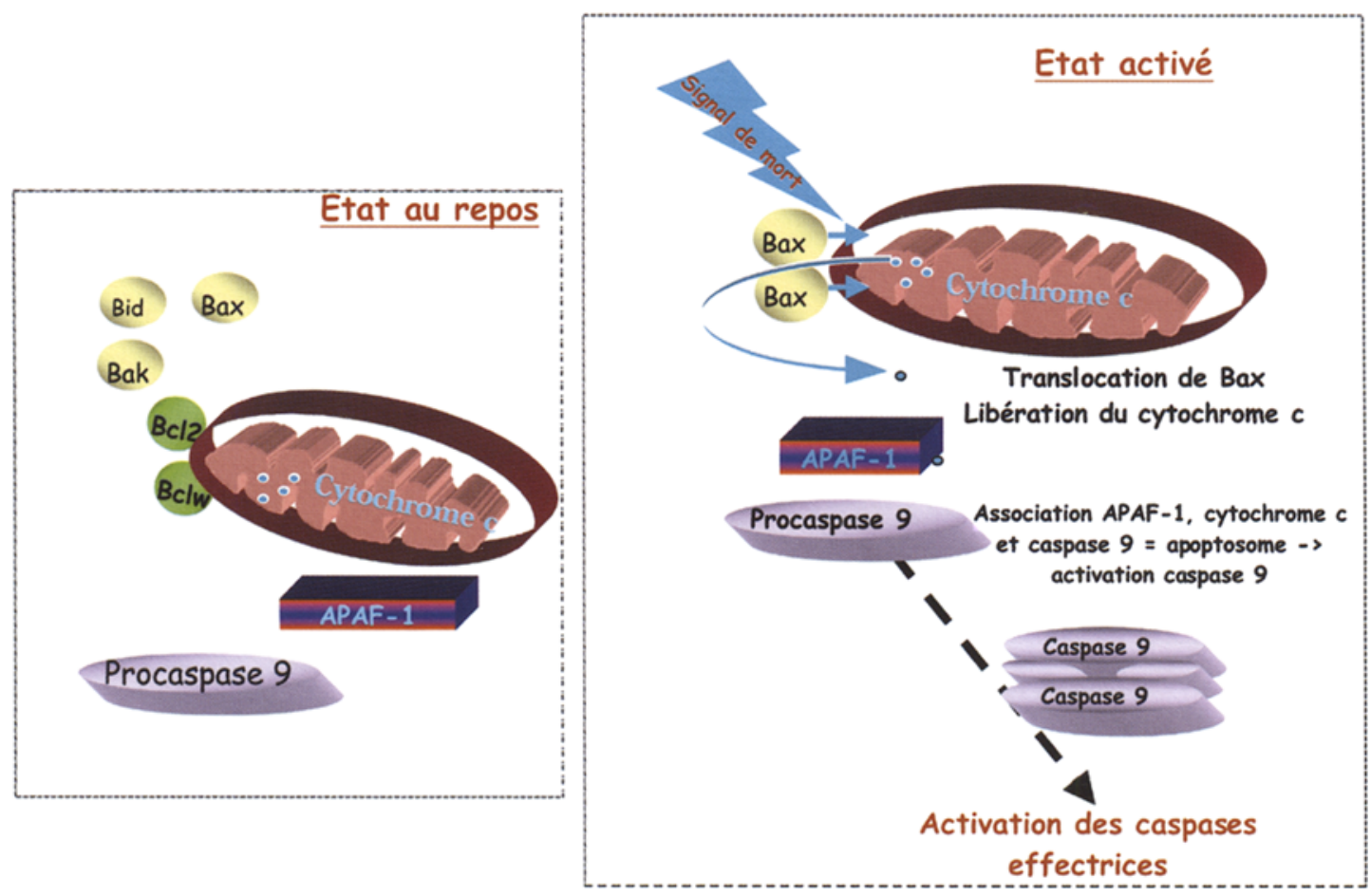

Figure 3 : Schéma d'activation de la voie mitochondriale. 


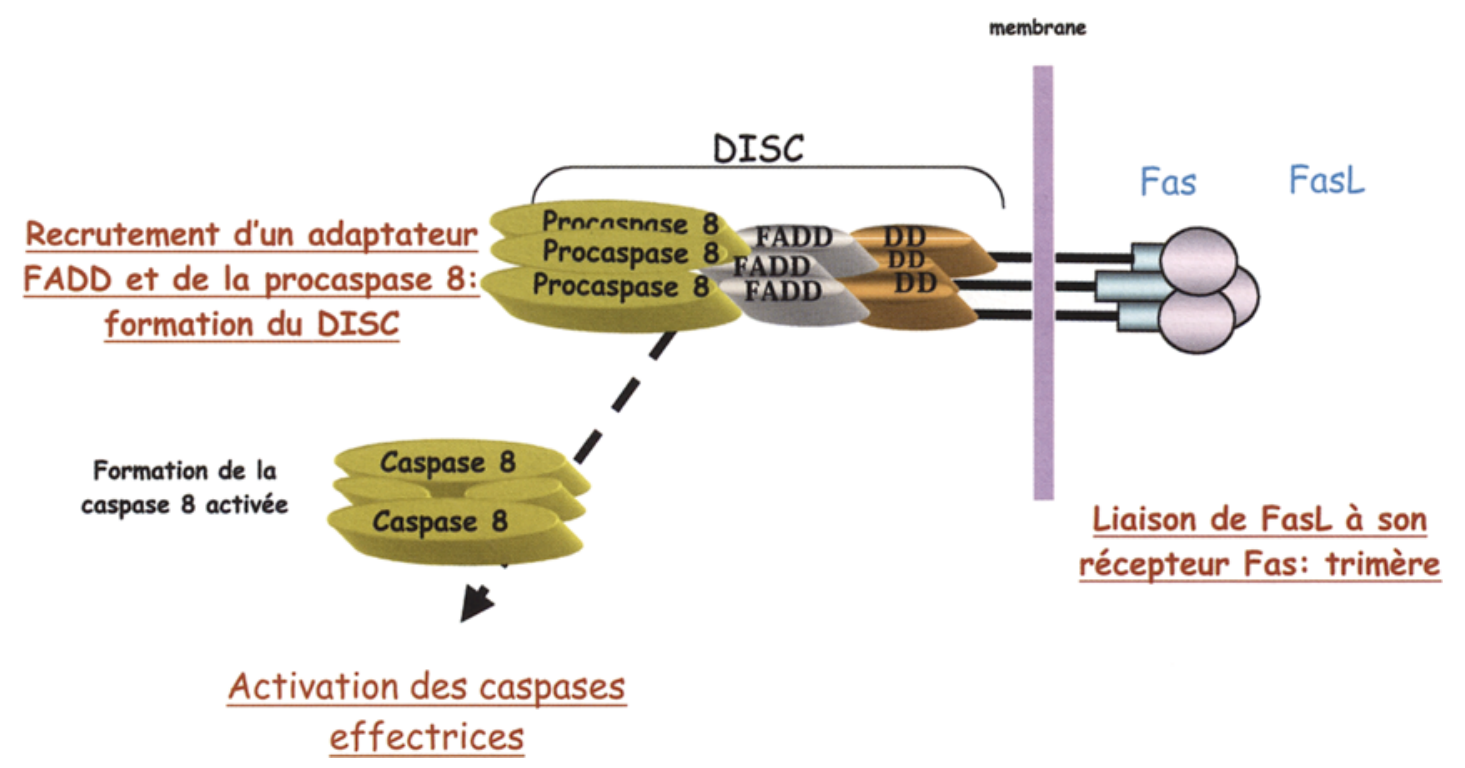

Figure 4 : Voies de régulation des caspases.

participant au maintien de l'intégrité cellulaire [52; 70]. Parmi les substrats des caspases, on connaît la protéine PARP (poly (ADP-ribose) polymérase) qui participe au système de réparation de l'ADN. Le clivage de PARP par les caspases, survient en même temps que celui d'autres enzymes de réparation de l'ADN et de protéines structurales nucléaires. La réparation de l'ADN n'est plus possible, le programme de mort cellulaire par apoptose devient irréversible. La fragmentation de l'ADN est accompagnée de la condensation du cytoplasme et des mitochondries. La membrane plasmique externe "se retourne" exposant alors des molécules de phosphatidylsérines. Puis un bourgeonnement de la membrane est observé ainsi que la division du cytoplasme en vésicules (nommées corps apoptotiques) qui seront phagocytées par les cellules avoisinantes (Figure 1)

\section{L'APOPTOSE AU COURS DE LA SPERMATOGENESE NORMALE}

Depuis une dizaine d'années, différentes études ont souligné l'importance de l'apoptose au cours des différentes étapes de formation de la gonade mâle, par exemple, lors du remplacement des cellules de Leydig fœtales, ou de la production des gamètes mâles. Dans le cadre de la spermatogenèse l'apoptose intervient lors de la mise en route de la spermatogenèse, à la puberté, puis dans le testicule adulte, en régulant et contrôlant le déroulement des différentes étapes de la spermatogenèse.

\section{Apoptose des cellules germinales au cours du déve- loppement}

Au cours du développement, deux pics de forte apoptose des cellules germinales ont été décrits. Pendant la vie fœtale, les cellules germinales primordiales (CGPs) colonisent la crête génitale à 11,5 jours post-coitum chez la souris. Les CGPs prolifèrent activement du gème au 15 ème jour puis subissent un premier pic d'apoptose entre le 13 ème et le
17 ème jour post-coitum [125]. Un deuxième pic d'apoptose est observé à la puberté, lors de la première vague de la spermatogenèse. A cette période l'apoptose touche particulièrement les spermatocytes pachytènes aux stades VIIVIII. Cette apoptose culmine approximativement deux ou trois semaines après la naissance chez la souris et le rat $[89,124,138,139]$. L'apoptose liée à la première vague de la spermatogenèse est critique et nécessaire pour le développement ultérieur et le fonctionnement normal du testicule adulte $[6,89]$.

\section{Apoptose lors de la spermatogenèse adulte}

Lors de la spermatogenèse normale, le nombre des cellules germinales dans les tubules séminifères du testicule est déterminé par un équilibre dynamique entre la prolifération des cellules germinales et leur mort par apoptose [131]. Théoriquement une spermatogonie, chez un rat, devrait générer 4096 spermatozoïdes. Cependant, ce rendement théorique est loin d'être atteint puisque on estime que 60$75 \%$ des cellules germinales disparaissent pendant le processus de la spermatogenèse, ces cellules étant éliminées principalement par l'apoptose, $[2,42,137]$. II semble que toute cellule germinale altérée soit systématiquement détruite, l'organisme ne souhaitant pas prendre de risque à effectuer une réparation qui pourrait être incomplète.

Dans le testicule mature, l'apoptose spontanée touche essentiellement les spermatogonies et les spermatocytes. Ainsi les spermatogonies de type $A 2, A 3$, et $A 4$ subissent dans deux cas sur trois une apoptose [2]. Cette apoptose est fonction du stade de l'épithélium séminifère puisque les spermatogonies $A 2, A 3$, et $A 4$ qui dégénèrent sont principalement auX stades I et XII-XIV [8, 42]. La différentiation des cellules germinales est commandée par des hormones ( $\mathrm{FSH}$, testostérone), et des facteurs de croissance, et a pour cadre les interactions cellulaires avec des cellules de Sertoli [141]. Les cellules de Sertoli, auxquelles sont attachées les cellules germinales, ne peuvent soutenir qu'un 
nombre limité de cellules germinales. Ainsi le nombre des cellules germinales doit être régulé pour corréler la capacité des cellules de Sertoli [19]. De cette manière le rapport entre les différents types de cellules germinales et les cellules de Sertoli demeure relativement constant lors de la spermatogenèse, la régulation de ce rapport est une condition importante pour la différentiation des cellules germinales [89].

Le corollaire de ces interactions entre les cellules de Sertoli et les cellules germinales est que des dommages causés aux cellules de Sertoli peuvent provoquer l'apoptose des cellules germinales [10]. Puisque les cellules germinales existent dans un environnement créé par des cellules de Sertoli, il est hautement probable que des signaux paracrines produits par les cellules de Sertoli régulent le processus de la mort des cellules germinales. L'apoptose des cellules germinales peut être induit par une diminution des facteurs de survie et/ou une augmentation des facteurs proapoptotiques provenant des cellules de Sertoli. Ainsi lors d'un stress oxydatif testiculaire les protéines NF-kB exprimées par les cellules de Sertoli exercent des effets proapoptotiques sur des cellules germinales, ce qui soulève la possibilité que l'inhibition pharmacologique de NF-kB pourrait être une cible thérapeutique dans des situations passagères de stress oxydatif impliquant la mort excessive des cellules germinales [82].

Les hormones (FSH, testostérone, estradiol), les facteurs paracrines comme le facteur de croissance sertolien (SCF), le système $\mathrm{Fas} / \mathrm{FasL}$, et les protéines de la famille $\mathrm{Bcl}-2$ sont impliqués dans le contrôle de l'apoptose des cellules germinales [85, 102, 103]. II est évident que ces facteurs endocrines, paracrines et autocrines forment un réseau de signaux complexe du processus survie/mort des cellules germinales à travers les interactions entre cellules de Sertoli et cellules germinales $[74,87]$.

\section{LOCALISATION DES MOLÉCULES DE LA CASCADE APOPTOTIQUE DANS LE TESTICULE}

\section{Voie des récepteurs de mort}

Les trois systèmes de récepteur de mort ont été détectés dans le testicule. Concernant le système Fas/FasL, la majorité des travaux indiquent que le ligand FasL est porté par les cellules de Sertoli alors que le récepteur Fas est exprimé par les cellules germinales (spermatogonies chez les rongeurs $[63 ; 81 ; 108]$, spermatocytes primaires chez l'homme [29]). Toutefois, les travaux de Rossi ont suggéré une localisation différente : cellules germinales pour le ligand FasL et cellules de Sertoli pour son récepteur Fas [90]. II a été démontré que le système Fas contribue à l'homéostasie des cellules germinales [29], à travers les interactions cellules de Sertoli-cellules germinales [81, 108]. Ainsi le traitement des cellules de Sertoli par certaines toxines telles que (mono-(2-ethylhexyl) phthalate et 2,5-hexanedione) [62] conduit à la mort des cellules germinales ainsi qu'à une diminution de l'expression de FasR à la surface des cellules germinales. De plus, il a été suggéré que l'expression de FasL par les cellules de Sertoli permettaient la destruction de lymphocytes activés (exprimant Fas) ; ce serait un des moyens pour les cellules de Sertoli de maintenir un site immunologiquement privilégié dans le testicule [64].

La présence du système TNF/TNFR1 a été caractérisée dans les testicules des mammifères. Le ligand TNF alpha est produit par les spermatides rondes, les spermatocytes pachytènes et les macrophages testiculaires présents dans l'espace interstitiel $[20,71]$. Le récepteur de type TNF1-R1 a été trouvé au niveau des cellules de Sertoli et des cellules de Leydig $[12,67,68,109]$. Si le TNF-R1 est capable d'induire l'apoptose, son implication dans la mort programmée des cellules testiculaires est mal connue.

TRAIL (Tumor necrosis factor-alpha-related apoptosis-inducing ligand) et ses récepteurs ont été étudiés dans le testicule de rat pendant le développement. Le ligand TRAIL, les récepteurs induisant le signal apoptotique tel que DR5 et DR4 ainsi que les récepteurs leurres DcR1 et DcR2 sont localisés dans les différents types cellulaires du testicule. Le ligand TRAIL est présent dans les cellules de Leydig et dans les tubules séminifères. TRAIL est fortement exprimé dans les spermatides rondes et les spermatides allongées selon les stades du cycle de l'épithélium séminifère. Chez un rat adulte, le récepteur DR4 est détecté dans les spermatides aliongées et dans les corps résiduels. Les récepteurs DR5, DcR2 et DcR1 sont localisés au niveau des cellules de Leydig, dans les spermatides rondes et allongées selon le stade du cycle de l'épithélium séminifère, chez le rat adulte [33].

\section{Voie mitochondriale}

Les études employant des souris transgéniques suggèrent la participation de protéines pro- ou anti-apoptotiques de la famille $\mathrm{Bcl}_{2}$ dans la régulation de l'apoptose des cellules germinales. L'invalidation ou la sur expression de ces gènes entraînent souvent une infertilité et sont autant de modèles expérimentaux pour l'étude de l'apoptose dans le testicule (Tableau 2).

Un grand nombre de protéines de la famille $\mathrm{BCl}_{2}$ a été identifié dans la gonade mâle $[41,59,89,116]$. De nombreux travaux effectués sur les protéines pro-apoptotiques de la famille $\mathrm{Bcl}_{2}$ ont monté que

- Bax est fortement détectée dans le noyau des spermatides rondes et dans quelques spermatocytes primaires, également dans le cytoplasme de d'autres cellules tubulaires chez l'homme [77]. Les travaux de Yan et al. chez le rat suggèrent que Bax a une localisation spécifiquement cytoplasmique dans les cellules de Sertoli, les spermatogonies et les spermatocytes et non dans les spermatides. Bax semble faiblement exprimé dans les cellules de Leydig [138]. D'autres études réalisées sur le rat confirme que la localisation de Bax est dans les cellules de Leydig et surtout dans les cellules germinales méiotiques [11].

- Bak est préférentiellement exprimé dans le cytoplasme des cellules de Sertoli, des spermatocytes et des spermatogonies chez le rat $[11,138]$, dans les spermatides 
Tableau 2 : invalidation de molécules de la famille Bcl, effet sur la gonade mâle.

\begin{tabular}{|c|c|c|c|}
\hline Gène muté & Phénotype & Fertilité & Références \\
\hline $\mathrm{Bc} \mid 6$ & $\begin{array}{l}\text { Apoptose des spermatocytes } \\
\text { en métaphase }\end{array}$ & hypofertilité & [58] \\
\hline $\mathrm{Bcl} 2$ & $\begin{array}{l}\text { Blocage de la mort cellulaire, } \\
\text { désorganisation de la spermatogenèse }\end{array}$ & infertilité & {$[30,89]$} \\
\hline $\begin{array}{l}\text { Bax (Bcl2-associated } \\
\text { X protein) }\end{array}$ & $\begin{array}{l}\text { Arrêt de la spermatogenèse au } \\
\text { stade préméiotique }\end{array}$ & Infertilité & {$[56,83]$} \\
\hline Bclx & $\begin{array}{l}\text { Les CGPs disparaissent au 15,5ème jours } \\
\text { post -coitum }\end{array}$ & infertilité & [92] \\
\hline Bclw & $\begin{array}{l}\text { Arrêt/retard de la phase méiotique avec } \\
\text { perte de cellules germinales }\end{array}$ & infertilité & {$[58]$} \\
\hline
\end{tabular}

un marquage membranaire plus intense est observé par rapport au marquage cytoplasmique. Un faible marquage de base au niveau des spermatogonies est observé chez l'homme [77].

- Bad est exprimé au niveau des spermatides rondes et allongées, également dans les spermatozoïdes, plus spécifiquement dans l'acrosome, chez l'homme [77].

- Bid a été localisé exclusivement dans les spermatides rondes et allongées chez le rat adulte [11].

La localisation des protéines anti-apoptotiques de la famille $\mathrm{Bcl}_{2}$ a été également étudiée chez l'homme et le rat.

- La protéine $\mathrm{Bcl}_{2}$ est détectée dans les cellules du tubule séminifère avec une localisation préférentielle dans le cytoplasme des spermatides différenciées près de la lumière du tube chez l'homme [77]. Chez le rat adulte $\mathrm{Bcl}-2$ est détectée dans les cellules de Leydig et les spermatocytes pachytènes [11].

- Bcl-x a été localisé au niveau du cytoplasme des spermatogonies chez l'homme [77].

- Bcl-w est localisé au niveau des cellules somatiques de Leydig et de Sertoli et surtout dans les cellules germinales préméiotiques chez le rat adulte [11]. Les travaux de Yan et al. suggèrent que Bcl-w a une localisation semblable à celle de Bax et Bak mais plus intense dans les cellules de Sertoli comparé aux spermatogonies et aux spermatocytes [138].

- Enfin Mcl-1 est faiblement exprimé au niveau de la partie basale de l'épithélium séminifère chez l'homme [77].

\section{Les caspases}

Dans les testicules de rat adulte, les caspases effectrices telles que les caspases 3,6 et 7 ont été détectées : la procaspase- 3 a été spécifiquement détectée dans les cellules de Leydig et les cellules germinales, plus précisément dans les spermatocytes pachytènes. La caspase- 3 activée est localisée exclusivement dans les cellules germinales post méiotiques en particulier dans les spermatides rondes [78]. D'autres études montrent que la localisation de la caspase3 activée est observée de façon dispersée dans le cytoplasme ou dans la région périnucléaire des cellules germinales [54]. Les travaux de Hikim et al. suggèrent que la localisation de la forme activée de la caspase-3 est spécifique des cellules pachytènes [40]. La procaspase- 6 est faiblement exprimée dans les cellules germinales particulièrement dans les spermatocytes pachytènes, également dans les cellules de Leydig [78]. La forme activée de la caspase6 a été détectée dans les spermatocytes pachytènes [40]. La forme active de la caspase- 7 a été détectée aussi au niveau des cellules pachytènes de rat [40].

Les caspases initiatrices ont fait également l'objet de plusieurs études chez le rat. La caspase -2 est localisée au niveau des cellules germinales au niveau de la périphérie du tubule séminifères [143]. La caspase-1 a été décrite chez le rat au niveau du cytoplasme des spermatides [9]. La forme active de la caspase-9 a été détectée au niveau des spermatocytes pachytènes chez le rat [40]. Enfin, la procaspase- 8 a été détectée dans le cytoplasme des cellules de Leydig et les cellules germinales (spermatocytes pachytènes) sous la forme d'un marquage punctiforme [78].

\section{INDUCTION DE L'APOPTOSE DANS LES CELLULES GERMINALES : MODËLE ANIMAL}

L'induction de l'apoptose dans les cellules germinales peut être causée par plusieurs facteurs tels que : le retrait hormonal, la cryptorchidie, l'hyperthermie ou les rayons ionisants.

\section{Retrait hormonal}

L'hormone folliculo-stimulante (FSH) permet le développement des cellules de Sertoli et le bon déroulement de la spermatogenèse. La FSH est le facteur méiotique principal des cellules de Sertoli [79], alors que la LH (hormone luté- 
nisante) assure la multiplication des cellules de Leydig et la sécrétion de la testostérone. Les gonadotrophines et la testostérone sont connues pour avoir une forte influence sur le déroulement de la spermatogenèse puisque leur retrait induit l'apoptose des cellules germinales. Toutefois, l'action de ces hormones est indirecte, car leurs récepteurs sont présents uniquement sur les cellules somatiques (cellules de Leydig, cellules de Sertoli) et non sur les cellules germinales.

Les souris invalidées pour le gène de la FSH, présentent des testicules de petite taille mais sont fertiles $[22,38,60]$. La privation de $\mathrm{FSH}$ est responsable chez ces animaux d'une réduction du diamètre des tubes séminifères, du nombre de cellules de Sertoli et par conséquent du nombre des cellules germinales. Une diminution de la mobilité des spermatozoïdes est notée bien que les souris mutantes soient fertiles $[22,38,60,107]$. Le déficit en FSH chez des rats adultes conduit à une réduction de $90 \%$ en spermatides rondes et une augmentation de $260 \%$ en spermatogonies et de $90 \%$ des spermatocytes. Il a été constaté également que la conversion des spermatogonies en spermatocytes est réduite de $26 \%$ [120]. La privation de $\mathrm{FSH}$ à l'âge adulte, provoque la mort des spermatogonies lors de leur dernière division mitotique, suggérant ainsi que la FSH est indispensable pour la dernière division spermatogoniale précédant le déclenchement de la méiose [113]. Le retrait hormonal ne produit aucun effet sur l'activation des caspases bien qu'il y ait une augmentation de la fragmentation de l'ADN observée au niveau des noyaux des spermatides. Cela suggère que, à la différence de l'apoptose physiologique pendant la spermatogenèse normale, les changements apoptotiques qui se produisent au niveau des cellules germinales en réponse au retrait de la FSH se font de façon caspase indépendante [113].

Un déficit isolé en $\mathrm{LH}$ peut être associé à une oligospermie ou une azoospermie, ou un arrêt de maturation de la spermatogenèse. Le mécanisme par lequel la suppression de cette hormone induit l'apoptose est encore mal connu. Des études de privation de LH (donc de testostérone) montrent leurs effets néfastes sur la spermatogenèse. Cela se traduit par une diminution de la testostérone 2 à 4 semaines après ce retrait, ainsi qu'une réduction rapide et une absence complète des spermatides rondes et allongées. L'effet immédiat de la privation en LH/testostérone se produit à l'étape de la transformation méiotique des spermatocytes primaires en spermatides. De plus, une réduction de la population des spermatocytes et une accumulation des spermatogonies ont été observées, ce qui suggére l'importance de la $\mathrm{LH} /$ testostérone dans l'étape de la formation des spermatocytes [46]. Une privation prolongée de LH in vitro par un traitement à la testostérone/estradiol (TE) conduit à une altération morphologique des cellules de Leydig. Le volume de ces cellules diminue progressivement après traitement mais pas leur nombre. Les cellules de Leydig perdent $90 \%$ de leur volume cytoplasmique et $65 \%$ du volume nucléaire associé à une diminution de la sécrétion de la testostérone $[50,51]$.

L'inhibition de l'action ou de la synthèse de la testostérone à l'âge adulte a été largement montrée comme induisant une apoptose des cellules germinales. La suppression de la testostérone intra testiculaire par un antagoniste de la GnRH peut être responsable de la réduction immédiate du nombre des spermatozoïdes [100]. Le traitement quotidien des testicules avec un antagoniste de la $\mathrm{GnRH}$ induit une activation de l'apoptose des cellules germinales selon leur situation dans les stades de l'épithélium séminifère. Après 5 jours de traitement l'apoptose atteint les cellules germinales préleptotènes et les spermatocytes pachytènes, aux stades VII-VIII (stades androgéno-dépendants) puis les stades IX$\mathrm{XI}$ entre le 5éme et le 7éme jour du traitement $[97,102]$. Ainsi l'apoptose joue un rôle principal dans la régression progressive et organisée de la spermatogenèse après une privation androgénique $[102,104]$. L'apoptose des cellules germinales, résultant d'une diminution du taux intra testiculaire de la testostérone, est due à une activation dans les spermatocytes et les spermatides de la caspase effectrice 3 [54 78], au clivage de son substrat PARP et à l'activation de desoxyribonucléases [54]. En amont, les caspases effectrices seraient activées par la voie mitochondriale et/ou la voie des récepteurs de mort. L'activation des caspases se produit aussi dans les cellules de Sertoli, ce phénomène coïncide avec une augmentation progressive de la proportion des cellules de Sertoli montrant des fragmentations d'ADN $[54,113]$. L'apoptose des cellules germinales après un retrait in vitro de la testostérone ne se produit qu'après un changement primaire au niveau des cellules de Sertoli [113]. La suppression des androgènes altère l'expression des protéines de la famille $\mathrm{Bcl}_{2}[85,86,132,133]$. Ainsi, la privation de testostérone provoque une altération de la protéine pro-apoptotique Bax dans les spermatocytes pachytènes, cibles de l'apoptose [138]. De plus, le système Fas/FasL semble aussi être une voie de régulation de l'apoptose dans ce modèle. Cela se traduit par une augmentation du contenu testiculaire en Fas et de l'action autocrine du ligand Fas, dans le testicule ayant subi une privation de la testostérone $[61,75,113]$.

Enfin, si la privation en testostérone chez l'adulte provoque une apoptose massive des cellules germinales, celle-ci est réversible à l'arrêt du traitement [78]. En revanche, la privation in utero en testostérone pendant la vie fœtale provoque des altérations beaucoup plus dramatiques, car irréversibles. L'exposition in utero à des composés possédant des activités anti androgéniques tels que des pesticides $[11,27$, 34-36], des esters de phthalates provenant de matières plastiques [73] et des médicaments comme le flutamide [11, $44,78]$ provoquent des malformations chroniques de l'appareil génital mâle. Ces altérations sont, l'hypospermatogenèse, la cryptorchidie et l'hypospadias. Ces altérations morphologiques sont, dans le testicule, le résultat d'une activation chronique de l'apoptose des cellules germinales aux stades VII et VIII (androgéno-dépendants) de l'épithélium séminifère [11]. Cette apoptose chronique est liée à une activation des caspases effectrices 3 et 6 et en amont, à l'activation de la voie mitochondriale [11, 78]. L'apoptose chronique des cellules germinales adultes serait liée à des altérations fonctionnelles des cellules de Sertoli comme par exemple leur capacité réduite à produire du lactate [32]. En 
somme, une exposition in utero à des antiandrogènes provoquerait une programmation fœtale d'une " pathologie " se déclarant à l'âge adulte. Ces résultats expérimentaux sont à rapprocher d'études épidémiologiques réalisées chez l'homme. Ainsi, il a été noté une diminution de la qualité du sperme (quoique controversée), une augmentation de l'incidence du cancer du testicule et de l'hypospadias. Ces trois symptômes seraient liés et appartiendraient à un même syndrôme, la dysgénesie testiculaire [105]. Etant donné les informations apportées par les modèles expérimentaux, le syndrôme de dysgénésie testiculaire pourrait être lié à une exposition intra utérine à des antiandrogènes.

\section{Cryptorchidie}

Bien que la cryptorchidie soit associée à une spermatogenèse altérée, les mécanismes conduisant à la diminution de la production des spermatozoïdes sont encore mal connus. En 1995, Henriksen et al. [39] ont identifié la présence d'une apoptose accrue des cellules germinales 24 à 48 heures après l'induction d'une cryptorchidie expérimentale chez le rat ; ceci concerne tous les stades de l'épithélium séminifère exceptés les stades VI et VIII [43, 98]. D'autres études montrent un arrêt de la spermatogenèse aux stades IX et $X$ ainsi qu'une absence de cellules haploides matures dans les testicules de hamster après induction d'une cryptorchidie expérimentale, ainsi qu'une diminution des cellules tétraploïdes et une augmentation du nombre des cellules en phase $\mathrm{S}$. Ces données suggèrent que la cryptorchidie affecte la maturation des spermatides, perturbe le processus de condensation de l'ADN [123], provoquant une diminution du nombre de spermatides et de spermatozoïdes une semaine après l'induction d'une cryptorchidie expérimentale [45]. La cryptorchidie provoque une réduction du taux de fécondité qui est de $44 \%$ pour les rats rendus cryptorchides contre $90 \%$ pour les rats témoins [127]. Les effets néfastes de la cryptorchidie sur l'histologie testiculaire sont détectés par une diminution du diamètre moyen des tubes séminifères et une diminution du nombre des cellules germinales [23], ce qui correspond à une hypospermatogenèse diffuse [144]. II existe une corrélation entre l'ampleur de l'activité apoptotique des cellules germinales et la durée de la cryptorchidie expérimentale [5]. Chez le rat cryptorchide, l'apoptose des cellules germinales est un mécanisme prédominant [57]. Les travaux de Henriksen et al. indiquent que les spermatocytes primaires sont les principales cellules affectées par la cryptorchidie expérimentale [39]. L'apoptose induite par la cryptorchidie, implique la voie des récepteurs de mort via le système Fas/FasL [76], mais aussi la voie mitochondriale en entraînant des modifications de l'expression des protéines anti-apoptotique $\mathrm{Bcl}$ 2 et pro-apoptotique Bax [135]. Ainsi chez les animaux cryptorchides, il y a redistribution de Bax du cytoplasme vers le noyau des cellules germinales et une augmentation de l'expression de $\mathrm{Bcl}_{-2}$ dans le testicule cryptorchide du singe [142]. Lors de la cryptorchidie, les testicules en position abdominale sont exposés à une température plus élevée qu'en position scrotale [25]. Dans ces conditions, le rôle de la température dans les altérations testiculaires observées après cryptorchidie a été étudié [45]. II semble que la dégé- nérescence des cellules germinales par apoptose après induction d'une cryptorchidie soit aussi le résultat de l'exposition des cellules à la température abdominale [135], empêchant la plupart des spermatocytes d'effectuer la méiose et la différentiation des spermatides en spermatozoïdes [45] (voir chapitre suivant).

Enfin, la cryptorchidie provoque aussi des altérations au niveau des cellules de Sertoli, en effet une diminution des récepteurs de l'IGF-l a été observée dans ces cellules [3]. Le cytosquelette des cellules de Sertoli joue un rôle important au cours de la spermatogenèse et chez les rats cryptorchides les cellules de Sertoli présentent un changement de distribution des filaments de vimentine, lesquels sont importants pour maintenir l'intégrité structurale de l'épithélium séminifère. Cette redistribution est corrélée à l'apoptose accrue des cellules germinales et à une perte du poids des testicules [141].

\section{L'hyperthermie}

La fonction testiculaire normale exige une température 2$4^{\circ} \mathrm{C}$ au-dessous de la température du corps $[13,55,69]$. L'exposition professionnelle à la chaleur représente un facteur de risque pour la fertilité masculine, se traduisant par une atteinte de la morphologie ainsi qu'une diminution de la mobilité des spermatozoïdes [69, 114]. L'hyperthermie testiculaire a comme conséquence l'azoospermie et l'oligozoospermie chez les rongeurs et les singes par apoptose accrue des cellules germinales [66]. L'hyperthermie induit l'apoptose des cellules germinales d'une façon stade spécifique. L'hyperthermie des testicules chez le rat même pendant un temps court de 1 à 2 jours, entraîne l'apoptose des cellules germinales au niveau des stades I-IV et XII-XIV de l'épithélium séminifère. Tandis que les stades $V-V \mid$ et VIIVIII sensibles aux androgènes ne sont pas affectés. Cela suggère que la testostérone jouerait un rôle protecteur au niveau des stades VII-VIII contre la mort provoquée par la chaleur. Cependant, la participation possible de divers facteurs tels que les facteurs de croissance, I'IGF, les thermoprotecteurs Hsp70 et les cytokines IL 1 ou 2 est possible. Les dommages dus à la chaleur sont réversibles [65].

L'initiation de l'apoptose des cellules germinales est précédée par une redistribution de la protéine Bax du cytoplasme vers la périphérie du noyau, au niveau du réticulum endoplasmique des spermatocytes pachytènes, mais les taux des protéines en eux mêmes ne sont pas affectés [93]. La délocalisation de Bax est accompagnée d'une libération du cytochrome c, d'une activation des caspases 9,3 et 7 et d'un clivage de la protéine PARP. De plus, l'exposition des testicules à la chaleur ne conduit pas à l'activation de Fas/FasL [136]. En parallèle, il y a augmentation des taux protéiques de $\mathrm{Bcl}-2$ mais pas de ses ARNm après exposition à la chaleur.

\section{Rayons ionisants}

Dans le cas de la mort cellulaire radio-induite, l'apoptose survient généralement après la mitose. Les cassures double brins de l'ADN, non réparées ou mal réparées sont considérées comme les lésions critiques menant à l'apop- 
tose radio-induite [110]. Les cellules endommagées par les rayonnements ionisants ne meurent pas nécessairement immédiatement après irradiation mais peuvent se diviser plusieurs fois avant d'atteindre un niveau critique d'instabilité génomique. II est connu depuis longtemps que les cellules testiculaires sont particulièrement sensibles aux rayonnements ionisants mais leur sensibilité n'est pas identique. Ainsi, les cellules de la lignée germinale les moins différenciées (gonocytes, précurseurs foetaux et spermatogonies $A$ et $B$ ) sont les plus sensibles. La sensibilité des cellules germinales aux irradiations est dépendante de leur stade de développement [47]. II a été observé une augmentation des dommages de leur ADN avec l'intensité de l'irradiation [16]. La radiosensibilité des gonocytes augmente avec l'âge fœtal et la position des gonocytes dans le testicule au moment de l'irradiation semble être un paramètre important dans l'induction de l'apoptose [72]. Chez le rat, le seuil de radiosensibilité des gonocytes est de $0,2 \mathrm{~Gy}$ [122]. L'exposition aux rayonnements $X$ des spermatogonies $B$ en phase $S$ de mitose entraîne un retard de leur progression vers la méiose, alors que l'irradiation des spermatocytes préleptotènes n'affecte pas leur progression dans la phase G1 du cycle cellulaire en dépit des dommages observés au niveau de l'ADN [130]. L'apoptose radio induite des spermatogonies semble dépendante de la protéine p53 [7].

\section{APOPTOSE ET INFERTILITÉ MASCULINE}

Jusqu'ici, il n'était pas évident que l'apoptose dans les spermatozoïdes se produise de façon semblable à celle décrite dans des cellules somatiques car les spermatozoïdes ont un noyau transcriptionel presque inactif [31, 95]. De plus, les spermatozoïdes indemnes d'apoptose contiennent des caspases en faible quantité, alors que des échantillons provenant de patients stériles contiennent une quantité élevée de caspases effectrices, particulièrement dans les résidus cytoplasmiques.

L'utilisation d'inhibiteurs immunofluorescents des caspases activées a démontré clairement la présence post acrosomale et la fonctionnalité des caspases dans les spermatozoïdes éjaculés d'homme infertile [94]. L'expression des caspases est corrélée avec l'apparition des phospholipides phosphatidylsérines sur la membrane externe des spermatozoïdes d'homme stérile [94]. La présence des précurseurs et des formes activées des caspases initiatrices- 8 et -9 en même temps que la caspase- 3 effectrice dans les spermatozoïdes d'homme stérile a été également confirmée [94]. II a été observé également l'expression de la caspase-1 dans le cas d'infertilité $[37,106]$. Enfin l'ensemble des caspases activées $(8,1$ et 3$)$ ont été observées principalement dans la région post acrosomale des spermatozoïdes. En outre, la caspase- 9 effectrice activée a été localisée dans la pièce intermédiaire des spermatozoïdes. La présence et l'activité d'autres molécules impliquées dans l'apoptose telles que la p53, son partenaire MDM2 et PARP ont été détectées. Dans les spermatozoïdes d'homme infertile, la forme clivée de PARP n'a été détectée que dans $43 \%$ des échantillons. En outre, MDM2 et ses résidus clivés ont été trouvés dans $74 \%$ des échantillons, alors que dans $75-100 \%$ des échantillons étudiés, p53 était détectée par analyse protéique [94].

En somme, une apoptose accrue a été identifiée dans différentes anomalies du testicule, diminution de la mobilité des spermatozoïdes, torsion testiculaire et varicocèle [119].

\section{Effet sur la motilité des spermatozoïdes}

Les spermatozoïdes avec une faible motilité issus de patients en oligospermie montrent une activité caspase plus importante par rapport aux spermatozoïdes avec une forte motilité issus d'hommes fertiles. Des niveaux plus élevés de caspase- 3 activée et de pro caspase- 3 sont identifiés dans les fractions des spermatozoïdes de faible motilité comparées aux fractions de forte motilité [129]. En outre, des niveaux plus bas et plus variables de pro caspase-3 ont été observés dans les spermatozoïdes de forte motilité ainsi qu'une absence de caspase-3 activée. Cependant, l'addition d'un inhibiteur de caspase n'améliore en rien la motilité des spermatozoïdes [84]. L'activation des caspases dans les échantillons de spermatozoïdes de faible motilité peut être attribuée à la voie mitochondriale via le complexe du cytochrome c-Apaf-1, qui active la caspase-9 activant en cascade les caspases effectrices- $3,-6$ et -7 [115].

\section{Torsion testiculaire}

La torsion testiculaire est une urgence urologique désignée sous le nom du scrotum aigu. Les dommages testiculaires sont suivis d'une perte de la fonction endocrine et exocrine du testicule. Les travaux de Liu et al. montrent que trois jours après induction expérimentale d'une torsion testiculaire chez un rat adulte, il est observé une forte apoptose des cellules germinales par rapport au contrôle [63]. Cette apoptose s'accompagne d'une augmentation de l'expression de Bax et une diminution de l'expression de Bcl-2 [63, 80]. La voie des récepteurs de mort a été aussi impliquée, l'expression de Fas est augmentée après une torsion testiculaire expérimentale chez le rat [80]. La torsion testiculaire expérimentale induit une ischémie [117, 118]. II est observé une activation de la voie des caspases pendant l'apoptose dans le testicule après ischémie. L'ischémie induit la protéolyse de la caspase-3 et de PARP. L'utilisation d'inhibiteur de caspases avec un large spectre (z-VAD-fmk) réduit mais n'annihile pas la fragmentation de l'ADN et la protéolyse de PARP. Cela suggère que des caspases autres que la caspase- 3 sont impliquées dans l'évolution de l'apoptose pendant l'ischémie [99].

\section{Varicocèle}

L'apoptose peut avoir un rôle dans le développement de l'oligospermie pendant la varicocèle [53]. Les travaux de Barqawi et al. montrent qu'après induction d'une varicocèle expérimentale chez le rat on observe une apoptose accrue des cellules germinales [4, 134]. De même, chez les hommes affectés d'une varicocèle, une apoptose accrue des cellules germinales été aussi détectée [101]. Toutefois, les dommages testiculaires ne seraient pas identiques selon que c'est le testicule droit ou gauche qui est affecté par la varicocèle. Ainsi, des hommes stériles avec une varicocèle gauche présentent moins d'apoptose des cellules germina- 
les par rapport aux hommes fertiles [29]. Dans les testicules d'hommes stériles avec une varicocèle, les niveaux de ICE (interleukin-1b-converting enzyme) et de la caspase-3 sont sensiblement inférieurs par rapport aux hommes fertiles [111]. Cela suggére que l'apoptose serait supprimée en raison d'une expression diminuée de la caspase-3. Ces données restent encore contradictoires [53].

\section{CONCLUSION}

En somme, l'apoptose est un processus très important dans la régulation de la spermatogenèse. L'ensemble des acteurs de l'apoptose a été détecté dans les cellules germinales, les protéines sont régulées par les hormones ou leur activité est induite lors de certaines pathologies testiculaires. Les caspases semblent au cœur de l'apoptose chez l'homme aussi, une meilleur compréhension de leur implication dans l'apoptose des cellules germinales permettra peut être d'identifier de nouveaux outils diagnostiques pour les infertilités voire de nouveaux outils thérapeutiques (inhibiteurs de caspases).

\section{REFERENCES}

1. ADAMS J.M., CORY S. : The Bcl-2 protein family : arbiters of cell survival. Science, 1998, $281: 1322-1326$.

2. ALLAN D.J., HARMON B.V., ROBERTS S.A. : Spermatogonial apoptosis has three morphologically recognizable phases and shows no circadian rhythm during normal spermatogenesis in the rat. Cell Prolif., 1992, $25: 241-250$.

3. ANTICH M., FABIAN E., SARQUELLA J. et al. : Effect of testicular damage induced by cryptorchidism on insulin-like growth factor I receptors in rat Sertoli cells. J. Reprod. Fertil., 1995, $104: 267-275$.

4. BARQAWI A., CARUSO A., MEACHAM R.B. : Experimental varicocele induces testicular germ cell apoptosis in the rat. J. Urol, 2004, 171 : 501-503.

5. BARQAWI A., TRUMMER H., MEACHAM R. : Effect of prolonged cryptorchidism on germ cell apoptosis and testicular sperm count. Asian J. Androl., 2004, 6 : 47-51.

6. BARTKE A. : Apoptosis of male germ cells, a generalized or a cell type-specific phenomenon ? Endocrinology, 1995, 136 : 34.

7. BEUMER T.L., ROEPERS-GAJADIEN H.L., GADEMAN I.S. et al. : The role of the tumor suppressor $p 53$ in spermatogenesis. Cell Death Differ., 1998, $5: 669-677$.

8. BILLIG H., FURUTA I., RIVIER C. et al. : Apoptosis in testis germ cells : developmental changes in gonadotropin dependence and localization to selective tubule stages. Endocrinology, 1995, $136:$ 5-12.

9. BLANCO-RODRIGUEZ J., MARTINEZ-GARCIA C. : Apoptosis is physiologically restricted to a specialized cytoplasmic compartment in rat spermatids. Biol. Reprod., 1999, 61 : 15411547.

10. BOEKELHEIDE K., FLEMING S.L., JOHNSON K.J. et al. : Role of Sertoli cells in injury-associated testicular germ cell apoptosis. Proc. Soc. Exp. Biol. Med., 2000, 225 : 105-115.
11. BOZEC A, CHUZEL F, CHATER S. et al. : The mitochondrialdependent pathway is chronically affected in testicular germ cell death in adult rats exposed in utero to anti-androgens. J. Endocrinol., 2004, $183: 79-90$.

12. BUDNIK L.T., JAHNER D., MUKHOPADHYAY A.K. : Inhibitory effects of TNF alpha on mouse tumor Leydig cells : possible role of ceramide in the mechanism of action. Mol. Cell. Endocrinol., 1999, $150: 39-46$.

13. BUJAN L., MIEUSSET R. : Contraception masculine par la chaleur. Contracept. Fertil. Sex., 1995, $23: 611-614$.

14. CHAUDHARY P.M., EBY M., JASMIN A. et al. : Death receptor 5, a new member of the TNFR family, and DR4 induce FADDdependent apoptosis and activate the NF-kappaB pathway. Immunity, 1997, $7: 821-830$.

15. CONWAY E.M., POLLEFEYT S., CORNELISSEN J. et al. : Three differentially expressed survivin CDNA variants encode proteins with distinct antiapoptotic functions. Blood, 2000, 95 : 1435-1442.

16. CORDELLI E., FRESEGNAA.M., LETER G. et al. : Evaluation of DNA damage in different stages of mouse spermatogenesis after testicular X irradiation. Radiat. Res., 2003, $160: 443-451$.

17. CROMTON M. : Bax, Bid and the permeabilization of the mitochondrial outer membrane in apoptosis. Curr. Opin. Cell. Biol., $2000,12: 414-419$.

18. DATTA R., OKI E., ENDO K. et al. : XIAP regulates DNA damage-induced apoptosis downstream of caspase-9 cleavage. J. Biol. Chem., 2000, 275 : 31733-31738.

19. DE FRANCA L.R., GHOSH S., YE S.J. et al. : Surface and surface-to-volume relationships of the Sertoli cell during the cycle of the seminiferous epithelium in the rat. Biol. Reprod., 1993, $49: 1215-1228$.

20. DE S.K., CHEN H.L., PACE J.L. et al. : Expression of tumor necrosis factor-alpha in mouse spermatogenic cells. Endocrinology, 1993, 133 : 389-396.

21. DEVERAUX Q.L., REED J.C. : IAP family proteins--suppressors of apoptosis. Genes Dev., 1999, $13: 239-252$.

22. DIERICH A., SAIRAM M.R., MONACO L. et al. : Impairing follicle-stimulating hormone (FSH) signaling in vivo : targeted disruption of the $\mathrm{FSH}$ receptor leads to aberrant gametogenesis and hormonal imbalance. Proc. Natl Acad. Sci. USA, 1998, 95 : 13612-136177.

23. DUNDAR M., KOCAK I., CULHACI N. : A new experimental model for cryptorchidism : inguinoscrotal approach. Urol. Res., 2001, 29 : 178-181.

24. EVAN G., LITTLEWOOD T. : A matter of life and cell death. Science, 1998, $281: 1317-1322$.

25. FAROOQUI S.M., AL-BAGDADI F., HOUSLAY M.D. et al. : Surgically induced cryptorchidism-related degenerative changes in spermatogonia are associated with loss of cyclic adenosine monophosphate-dependent phosphodiesterases type 4 in abdominal testes of rats. Biol. Reprod., 2001, 64 : 1583-1589.

26. FELDAMN M., TAYLOR P., PALEOLOG E. et al. : Anti-TNF alpha therapy is useful in rheumatoid arthritis and Crohn's disease : analysis of the mechanism of action predicts utility in other diseases. Transplant Proc., 1998, $30: 4126-4127$.

27. FISHER J.S. : Environmental anti-androgens and male reproductive health : focus on phthalates and testicular dysgenesis syndrome. Reproduction, 2004, 127 : 305-315. 
28. FRANCAVILLA S., D'ABRIZIO P., RUCCI N. et al. : Fas and Fas ligand expression in fetal and adult human testis with normal or deranged spermatogenesis. J. Clin. Endocrinol. Metab., 2000,85 : 2692-2700.

29. FUJISAWA M., HIRAMINE C., TANAKA H. et al. : Decrease in apoptosis of germ cells in the testes of infertile men with varicocele. World J. Urol., 1999, 17 : 296-300.

30. FURUCHI T., MASUKO K., NISHIMUNE Y. et al. : Inhibition of testicular germ cell apoptosis and differentiation in mice misexpressing $\mathrm{Bcl}-2$ in spermatogonia. Development, 1996, 122 : 1703-1709.

31. GANDINI L., LOMBARDO F., PAOLI D. et al. : Study of apoptotic DNA fragmentation in human spermatozoa. Hum. Reprod., 2000, $15: 830-839$.

32. GODDARD I., FLORIN A., MAUDUIT C. et al. : Alteration of lactate production and transport in the adult rat testis exposed in utero to flutamide. Mol. Cell. Endocrinol., 2003, $206:$ 137-146.

33. GRATAROLI R., VINDRIEUX D., GOUGEON A. et al. : Expression of tumor necrosis factor-alpha-related apoptosisinducing ligand and its receptors in rat testis during development. Biol. Reprod., 2002, 66 : 1707-1715.

34. GRAY L.E. Jr., OSTBY J., FURR J. et al. : Perinatal exposure to the phthalates DEHP, BBP, and DINP, but not DEP, DMP, or DOTP, alters sexual differentiation of the male rat. Toxicol. Sci., $2000,58: 350-365$.

35. GRAY L.E. Jr., OSTBY J.S., KELCE W.R. : Developmental effects of an environmental antiandrogen : the fungicide vinclozolin alters sex differentiation of the male rat. Toxicol. Appl. Pharmacol., 1994, $129: 46-52$.

36. GRAY L.E. Jr., WOLF C., LAMBRIGHT C. et al. : Administration of potentially antiandrogenic pesticides (procymidone, linuron, iprodione, chlozolinate, p,p'-DDE, and ketoconazole) and toxic substances (dibutyl- and diethylhexyl phthalate, PCB 169, and ethane dimethane sulphonate) during sexual differentiation produces diverse profiles of reproductive malformations in the male rat. Toxicol. Ind. Health, 1999, $15: 94-118$.

37. GUPTA S., RADHA V., FURUKAWA Y. et al. : Direct transcriptional activation of human caspase- 1 by tumor suppressor $p 53$. J. Biol. Chem., 2001, 276 : 10585-10588.

38. HANEJI T., MAEKAWA M., NISHIMUNE Y. : Vitamin A and follicle-stimulating hormone synergistically induce differentiation of type A spermatogonia in adult mouse cryptorchid testes in vitro. Endocrinology, 1984, $114: 801-805$.

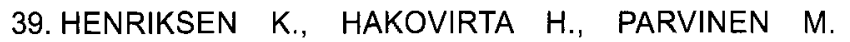
Testosterone inhibits and induces apoptosis in rat seminiferous tubules in a stage-specific manner : in situ quantification in squash preparations after administration of ethane dimethane sulfonate. Endocrinology, 1995, $136:$ 3285-3291.

40. HIKIM A.P., LUE Y., YAMAMOTO C.M. et al. : Key apoptotic pathways for heat-induced programmed germ cell death in the testis. Endocrinology, 2003, $144: 3167-3175$.

41. HOCKENBERY D.M., ZUTTER M., HICKEY W. et al. : BCL2 protein is topographically restricted in tissues characterized by apoptotic cell death. Proc. Natl Acad. Sci. USA, 1991, 88 : 6961-6965.

42. HUCKINS C. : The morphology and kinetics of spermatogonial degeneration in normal adult rats : an analysis using a simplified classification of the germinal epithelium. Anat. Rec., 1978, $190: 905-926$.
43. HULEIHEL M., LUNENFELD E. : Regulation of spermatogenesis by paracrine/autocrine testicular factors. Asian J. Androl., $2004,6: 259-268$.

44. IMPERATO-MCGINLEY J., SANCHEZ R.S., SPENCER J.R. et al. : Comparison of the effects of the 5 alpha-reductase inhibitor finasteride and the antiandrogen flutamide on prostate and genital differentiation : dose-response studies. Endocrinology, 1992, $131: 1149-1156$.

45. ITO K., TANEMURA K., GOTOH H. et al. : Apoptosis-like cell death in experimentally-induced cryptorchidism in adult mice. J. Vet. Med. Sci., 1997, $59:$ 353-359.

46. JEYAKUMAR M., SURESH R., KRISHNAMURTHY H.N. et al.: Changes in testicular function following specific deprivation of $\mathrm{LH}$ in the adult male rabbit. J. Endocrinol., 1995, $147: 111-120$.

47. JOSHI D.S., YICK J., MURRAY D. et al. : Stage-dependent variation in the radiosensitivity of DNA in developing male germ cells. Radiat. Res., 1990, $121: 274-281$.

48. KASOF G.M., GOMES B.C. : Livin, a novel inhibitor of apoptosis protein family member. J. Biol. Chem., 2001, 276 : 32383246.

49.KAYAGAKI N., KAWASAKI A., EBATA T. et al. : Metalloproteinase-mediated release of human Fas ligand. J. Exp. Med., $1995,182: 1777-1783$.

50. KEENEY D.S., MENDIS-HANDAGAMA S.M., ZIRKIN B.R. et al. : Effect of long term deprivation of luteinizing hormone on Leydig cell volume, Leydig cell number, and steroidogenic capacity of the rat testis. Endocrinology, 1988, $123: 2906-$ 2915.

51. KEENEY D.S., SPRANDO R.L., ROBAIRE B. et al. : Reversal of long-term LH deprivation on testosterone secretion and Leydig cell volume, number and proliferation in adult rats. J. Endocrinol., 1990, $127:$ 47-58.

52. KERR J.F., WYLLIE A.H., CURRIE A.R. : Apoptosis : a basic biological phenomenon with wide-ranging implications in tissue kinetics. Br. J. Cancer, 1972, $26: 239-257$.

53. KILINC F., GUVEL S., KAYASELCUK F. et al. : p53 Expression and apoptosis in varicocele int the rat testis. J. Urol., 2004, 172: 2475-2478

54. KIM J.M., GHOSH S.R., WEIL A.C. et al. : Caspase-3 and caspase-activated deoxyribonuclease are associated with testicular germ cell apoptosis resulting from reduced intratesticular testosterone. Endocrinology, 2001, 142 : 3809-3816.

55. KITAYAMA T. : [Study on testicular temperature in men]. Hinyokika Kiyo, 1965, $11: 435-465$.

56. KNUDSON C.M., TUNG K.S., TOURTELLOTTE W.G. et al. : Bax-deficient mice with lymphoid hyperplasia and male germ cell death. Science, 1995, $270: 96-99$.

57. KOCAK I., DUNDAR M., HEKIMGIL M. et al. : Assessment of germ cell apoptosis in cryptorchid rats. Asian J. Androl., 2002, $4: 183-186$.

58. KOJIMA S., HATANO M., OKADA S. et al. : Testicular germ cell apoptosis in Bcl6-deficient mice. Development, 2001, 128 : 57 65.

59. KRAJEWSKI S., BODRUG S., KRAJEWSKA M. et al. : Immunohistochemical analysis of $\mathrm{Mcl}-1$ protein in human tissues. Differential regulation of $\mathrm{Mcl}-1$ and $\mathrm{Bcl}-2$ protein production suggests a unique role for $\mathrm{Mcl}-1$ in control of programmed cell death in vivo. Am. J. Pathol., 1995, $146:$ 1309-1319. 
60. KRISHNAMURTHY P.K., MAYS J.L., BIJUR G.N. et al. Transient oxidative stress in SH-SY5Y human neuroblastoma cells results in caspase dependent and independent cell death and tau proteolysis. J. Neurosci. Res., 2000, 61 : 515-523.

61. LEE J., RICHBURG J.H., SHIPP E.B. et al. : The Fas system, a regulator of testicular germ cell apoptosis, is differentially upregulated in Sertoli cell versus germ cell injury of the testis. Endocrinology, 1999, $140: 852-858$.

62. LEE J., RICHBURG J.H., YOUNKIN S.C. et al. : The Fas system is a key regulator of germ cell apoptosis in the testis. Endocrinology, 1997, 138 : 2081-2088.

63. LIU Z.M., ZHENG X.M., LI S.W. et al. : Germ cell apoptosis and expression of $\mathrm{Bcl}-2$ and Bax following testicular torsion/detorsion in rats. Zhonghua Nan Ke Xue, 2003, $9: 40-42$.

64. LIU Z.P., LI W.Y., LIN B. et al. : Influence of FasL overexpression in transgenic mice on the immune regulative function of Sertoli cell. Xi Bao Yu Fen Zi Mian Yi Xue Za Zhi, 2004, 20 : 456-460.

65. LUE Y.H., HIKIM A.P., SWERDLOFF R.S. et al. : Single exposure to heat induces stage-specific germ cell apoptosis in rats: role of intratesticular testosterone on stage specificity. Endocrinology, 1999, $140: 1709-1717$.

66. LUE Y.H., LASLEY B.L., LAUGHLIN L.S. et al. : Mild testicular hyperthermia induces profound transitional spermatogenic suppression through increased germ cell apoptosis in adult cynomolgus monkeys (Macaca fascicularis). J. Androl., 2002, $23: 799-805$.

67. MAUDUIT C., BESSET V., CAUSSANEL V. et al. : Tumor necrosis factor alpha receptor p55 is under hormonal (folliclestimulating hormone) control in testicular Sertoli cells. Biochem. Biophys. Res. Commun., 1996, 224 : 631-637.

68. MAUDUIT C., HARTMANN D.J., CHAUVIN M.A. et al. : Tumor necrosis factor alpha inhibits gonadotropin action in cultured porcine Leydig cells : site(s) of action. Endocrinology, 1991, $129: 2933-2940$.

69. MIEUSSET R., BUJAN L. : Testicular heating and its possible contributions to male infertility : a review. Int. J. Androl., 1995, $18: 169-184$.

70. MIGNON A., GUIDOTTI J.E., MITCHELL C. et al. : Selective repopulation of normal mouse liver by Fas/CD95-resistant hepatocytes. Nat. Med., 1998, 4 : 1185-1188.

71. MOORE C., HUTSON J.C. : Physiological relevance of tumor necrosis factor in mediating macrophage-Leydig cell interactions. Endocrinology, 1994, $134: 63-69$.

72. MORENO S.G., DUTRILLAUX B., COFFIGNY H. : Status of p53, p21, mdm2, pRb proteins, and DNA methylation in gonocytes of control and gamma-irradiated rats during testicular development. Biol. Reprod., 2001, 64 : 1422-1431.

73. MYLCHREEST E., CATTLEY R.C., FOSTER P.M. : Male reproductive tract malformations in rats following gestational and lactational exposure to $\mathrm{Di}(\mathrm{n}$-butyl) phthalate : an antiandrogenic mechanism? Toxicol. Sci., 1998, $43: 47-60$.

74. NAGATA S., GOLSTEIN P. : The Fas death factor. Science, 1995, $267:$ 1449-1456.

75. NANDI S., BANERJEE P.P., ZIRKIN B.R. : Germ cell apoptosis in the testes of Sprague Dawley rats following testosterone withdrawal by ethane 1,2-dimethanesulfonate administration: relationship to Fas ? Biol. Reprod., 1999, 61 : 70-75.
76. OGI S., TANJI N., YOKOYAMA M. et al. : Involvement of Fas in the apoptosis of mouse germ cells induced by experimental cryptorchidism. Urol. Res., 1998, 26 : 17-21.

77. OLDEREID N.B., ANGELIS P.D., WIGER R. et al. : Expression of $\mathrm{Bcl}-2$ family proteins and spontaneous apoptosis in normal human testis. Mol. Hum. Reprod., 2001, 7 : 403-408.

78. OMEZZINE A., CHATER S., MAUDUIT C. et al. : Long-term apoptotic cell death process with increased expression and activation of caspase- 3 and -6 in adult rat germ cells exposed in utero to flutamide. Endocrinology, 2003, $144: 648-661$.

79. ORTH J.M. : Cell Biology of testicular development in fetus and neonate. In : Desjardins C., Ewing L.L. eds. Cell and molecular biology of testis. New York, Oxford University Press, 1993 : 3-4.

80. PAREDES ESTEBAN R.M., RAMIREZ CHAMOND R., CARRACEDE ANON J. et al. : [Valoration of the FAS in the contralateral testis after unilateral testicular torsion. Experimental study in rats]. Cir. Pediatr., 2003, 16 : 4-7.

81. PENTIKAINEN V., ERKKILA K., DUNKEL L. : Fas regulates germ cell apoptosis in the human testis in vitro. Am. J. Physiol., 1999, 276 : E310-E316.

82. PENTIKAINEN V., SUOMALAINEN L., ERKKILA K. et al. : Nuclear factor-kappa B activation in human testicular apoptosis. Am. J. Pathol., 2002, $160: 205-218$.

83. PEREZ G.I., ROBLES R., KNUDSON C.M. et al. : Prolongation of ovarian lifespan into advanced chronological age by Baxdeficiency. Nat. Genet., 1999, 21 : 200-203.

84. PETER A.T., LINDE-FORSBERG C. : Efficacy of the anticaspase agent zVAD-fmk on post-thaw viability of canine spermatozoa. Theriogenology, 2003, $59: 1525-1532$.

85. PRINT C.G., LOVELAND K.L. : Germ cell suicide : new insights into apoptosis during spermatogenesis. Bioessays, 2000, 22 : 423-430

86. PRINT C.G., LOVELAND K.L., GIBSON L. et al. : Apoptosis regulator bcl-w is essential for spermatogenesis but appears otherwise redundant. Proc. Natl Acad. Sci. USA, 1998, 95 : 12424-12431.

87. RICHBURG J.H. : The relevance of spontaneous- and chemically-induced alterations in testicular germ cell apoptosis to toxicology. Toxicol. Lett., 2000, 112-113:79-86.

88. RICHTER B.W., MIR S.S., EIBEN L.J. et al. : Molecular cloning of ILP-2, a novel member of the inhibitor of apoptosis protein family. Mol. Cell. Biol., 2001, $21: 4292-4301$.

89. RODRIGUEZ I., ODY C., ARAKI K. et al. : An early and massive wave of germinal cell apoptosis is required for the development of functional spermatogenesis. Embo. J., 1997, 16 : 2262-2270.

90. ROSSI P., DOLCI S., ALBANESI C. et al. : Follicle-stimulating hormone induction of steel factor (SLF) mRNA in mouse Sertoli cells and stimulation of DNA synthesis in spermatogonia by soluble SLF. Dev. Biol., 1993, 155 : 68-74.

91. ROY N., DEVERAUX Q.L., TAKAHASHI R. et al. : The c-IAP1 and C-IAP-2 proteins are direct inhibitors of specific caspases. Embo. J., 1997, $16: 6914-6925$.

92. RUCKER E.B. 3rd, DIERISSEAU P., WAGNER K.U. et al. : Bcl$X$ and Bax regulate mouse primordial germ cell survival and apoptosis during embryogenesis. Mol. Endocrinol., 2000, 14 : 1038-1052. 
93. RUSSELL L.D., CHIARINI-GARCIA H., KORSMEYER S.J. et al. : Bax-dependent spermatogonia apoptosis is required for testicular development and spermatogenesis. Biol. Reprod., 2002, $66: 950-958$.

94. SAID T.M., PAASCH U., GLANDER H.J. et al. : Role of caspases in male infertility. Hum. Reprod. Update, 2004, 10 : 39-51.

95. SAKKAS D., MOFFATT O., MANICARDI G.C. et al. : Nature of DNA damage in ejaculated human spermatozoa and the possible involvement of apoptosis. Biol. Reprod., 2002, 66 : 10611067.

96. SCHENDEL S.L., MONTAL M., REED J.C. : Bcl-2 family proteins as ion-channels. Cell. Death Differ., 1998, $5: 372-380$.

97. SHARPE R.M., KERR J.B., McKINNELL C. et al. : Temporal relationship between androgen-dependent changes in the volume of seminiferous tubule fluid, lumen size and seminiferous tubule protein secretion in rats. J. Reprod. Fertil., 1994, 101 : 193-198.

98. SHIKONE T., BILLIG H., HSUEH A.J. : Experimentally induced cryptorchidism increases apoptosis in rat testis. Biol. Reprod., 1994, $51: 865-872$.

99. SHIRAISHI K., NAITO K., YOSHIDA K. : Inhibition of calpain but not caspase protects the testis against injury after experimental testicular torsion of rat. Biol. Reprod., 2000, 63 : 15381548.

100. SHUTTLESWORTH G.A., DE ROOIJ D.G., HUHTANIEMI I. et al. : Enhancement of A spermatogonial proliferation and differentiation in irradiated rats by gonadotropin-releasing hormone antagonist administration. Endocrinology, 2000, $141: 37-$ 49.

101. SIMSEK F., TURKERI L., CEVIK I. et al. : Role of apoptosis in testicular tissue damage caused by varicocele. Arch. Esp. Urol., 1998, 51 : 947-950.

102. SINHA HIKIM A.P., RAJAVASHISTH T.B., SINHA HIKIM I, et al : Significance of apoptosis in the temporal and stage-specific loss of germ cells in the adult rat after gonadotropin deprivation. Biol. Reprod., 1997, 57 : 1193-1201.

103. SINHA HIKIM A.P., SWERDLOFF R.S. : Hormonal and genetic control of germ cell apoptosis in the testis. Rev. Reprod., 1999, $4: 38-47$.

104. SINHA HIKIM A.P., SWERDLOFF R.S. : Temporal and stagespecific changes in spermatogenesis of rat after gonadotropin deprivation by a potent gonadotropin-releasing hormone antagonist treatment. Endocrinology, 1993, $133: 2161-2170$.

105. SKAKKEBAEK N.E., RAJPERT-DE MEYTS E., MAIN K.M. : Testicular dysgenesis syndrome : an increasingly common developmental disorder with environmental aspects. Hum. Reprod., 2001, 16 : 972-978.

106. SOLARY E., EYMIN B., DROIN N. et al. : Proteases, proteolysis, and apoptosis. Cell. Biol. Toxicol., 1998, 14 : 121-132.

107. SRIRAMAN V., SAIRAM M.R., JAGANNADHA RAO A. : Evaluation of relative role of $\mathrm{LH}$ and $\mathrm{FSH}$ in restoration of spermatogenesis using ethanedimethylsulphonate-treated adult rats. Reprod. Biomed. Online, 2004, 8 : 167-174.

108. SUGIHARAA., SAIKI S., TSUJI M. et al. : Expression of Fas and Fas ligand in the testes and testicular germ cell tumors: an immunohistochemical study. Anticancer Res., 1997, 17 : 3861-3865.

109. SYLVESTER S.R., GRISWOLD M.D. : The testicular iron shuttle: a "nurse" function of the Sertoli cells. J. Androl., 1994, $15: 381-385$.

110. SZUMIEL I. : lonizing radiation-induced cell death. Int. J. Radiat. Biol., 1994, 66 : 329-341.

111. TANAKA H., FUJISAWA M., OKADA H. et al. : Apoptosis-related proteins in the testes of infertile men with varicocele. Brit. J. Urol. Int., 2002, 89 : 905-909.

112. TANAKA M., SUDA T., TAKAHASHI T. et al. : Expression of the functional soluble form of human fas ligand in activated lymphocytes. Embo. J., 1995, 14 : 1129-1135.

113. TESARIK J., MARTINEZ F., RIENZI L. et al. : In-vitro effects of $\mathrm{FSH}$ and testosterone withdrawal on caspase activation and DNA fragmentation in different cell types of human seminiferous epithelium. Hum. Reprod., 2002, 17 : 1811-1819.

114. THONNEAU P., BUJAN L., MULTIGNER L., MIEUSSET R. : Occupational heat exposure and male fertility : a review. Hum. Reprod., 1998, $13:$ 2122-2125.

115. THORNBERRY N.A., LAZEBNIK Y. : Caspases : enemies within. Science, 1998, $281: 1312-1316$.

116. TILLY J.L., TILLY K.I., KENTON M.L. et al. : Expression of members of the bcl-2 gene family in the immature rat ovary : equine chorionic gonadotropin-mediated inhibition of granulosa cell apoptosis is associated with decreased bax and constitutive bcl-2 and bcl-xlong messenger ribonucleic acid levels. Endocrinology, 1995, $136: 232-241$.

117. TURNER T.T. : Acute experimental testicular torsion. No effect on the contralateral testis. J. Androl., 1985, $6: 65-72$.

118. TURNER T.T., BROWN K.J. : Spermatic cord torsion : loss of spermatogenesis despite return of blood flow. Biol. Reprod., 1993, $49: 401-407$.

119. TURNER T.T., TUNG K.S., TOMOMASA H. et al. : Acute testicular ischemia results in germ cell-specific apoptosis in the rat. Biol. Reprod., 1997, 57 : 1267-1274.

120. VAISHNAV M., MOUDGAL N.R. : Role of FSH in regulating testicular germ cell transformations in the rat : a study using DNA flow cytometry. Andrologia, 1994, 26 : 111-117.

121. VARFOLOMEEV E.E., SCHUCHMANN M., LURIA V. et al. : Targeted disruption of the mouse Caspase 8 gene ablates cell death induction by the TNF receptors, Fas/Apo1, and DR3 and is lethal prenatally. Immunity, 1998, $9: 267-276$.

122.VERGOUVEN R.P., HUISKAMP R., BAS R.J. et al. : Radiosensitivity of testicular cells in the fetal mouse. Radiat. Res., 1995, $141:$ 66-73.

123. VIGODNER M., LEWIN L.M., SHOCHAT L. et al. : Evaluation of damage to the testicular cells of golden hamsters caused by experimental cryptorchidism using flow cytometry and confocal microscopy. Int. J. Androl., 2003, $26: 84-90$.

124. WANG R.A., NAKANE P.K., KOJI T. : Autonomous cell death of mouse male germ cells during fetal and postnatal period. Biol. Reprod., 1998, 58 : 1250-1256.

125. WANG Z.Q., TODANI T., WATANABE Y. et al. : Germ-cell degeneration in experimental unilateral cryptorchidism : role of apoptosis. Pediatr. Surg. Int., 1998, $14:$ 9-13.

126. WATANABE M. : Characteristics of TNF alpha- and TNF betainduced fever in the rabbit. Jpn. J. Physiol., 1992, $42: 101-$ 116. 
127.WATTS L.M., HASTHORPE S., FARMER P.J. et al. : Apoptotic cell death and fertility in three unilateral cryptorchid rat models. Urol. Res., 2000, 28 : 332-337.

128. WEI Y.H., LEE H.C. : Oxidative stress, mitochondrial DNA mutation, and impairment of antioxidant enzymes in aging. Exp. Biol. Med. (Maywood), 2002, 227 : 671-682.

129. WENG S.L., TAYLOR S.L., MORSHEDI M. et al. : Caspase activity and apoptotic markers in ejaculated human sperm. Mol. Hum. Reprod., 2002, 8 : 984-991.

130. WEST A., LAHDETIE J. : X-irradiation-induced changes in the progression of type $B$ spermatogonia and preleptotene spermatocytes. Mol. Reprod. Dev., 2001, 58 : 78-87

131. WILLIAMS G.T., SMITH C.A. : Molecular regulation of apoptosis : genetic controls on cell death. Cell, 1993, 74 : 777-779.

132.WOOLVERIDGE I., BRYDEN A.A., TAYLOR M.F. et al. : Apoptosis and expression of apoptotic regulators in the human testis following short- and long-term anti-androgen treatment. Mol. Hum. Reprod., 1998, 4 : 701-707.

133. WOOLVERIDGE I., DE BOER-BROUWER M., TAYLOR M.F. et al. : Apoptosis in the rat spermatogenic epithelium following androgen withdrawal : changes in apoptosis-related genes. Biol. Reprod., 1999, $60: 461-470$.

134. XIA Q., ZHANG X.B., ZHANG J. : The apoptosis in damaged testicular tissue caused by varicocele. Zhonghua Nan Ke Xue, 2002, $8: 414-415$.

135. XU J., XU Z., JIANG Y. et al. : Cryptorchidism induces mouse testicular germ cell apoptosis and changes in bcl-2 and bax protein expression. J. Environ. Pathol. Toxicol. Oncol., 2000, $19: 25-33$.

136. YAMAMOTO C.M., SINHA HIKIM A.P., HUYNH P.N. et al. : Redistribution of Bax is an early step in an apoptotic pathway leading to germ cell death in rats, triggered by mild testicular hyperthermia. Biol. Reprod., 2000, 63: 1683-1690.

137. YAN W., HUANG J.X., LAXA.S. et al. : Overexpression of Bcl$W$ in the testis disrupts spermatogenesis : revelation of a role of $\mathrm{BCL}-\mathrm{W}$ in male germ cell cycle control. Mol. Endocrinol., 2003, $17: 1868-1879$.

138. YAN W., SAMSON M., JEGOU B. et al. : Bcl-w forms complexes with Bax and Bak, and elevated ratios of $\mathrm{Bax} / \mathrm{Bcl}-\mathrm{W}$ and $\mathrm{Bak} / \mathrm{Bcl}-\mathrm{W}$ correspond to spermatogonial and spermatocyte apoptosis in the testis. Mol. Endocrinol., 2000, 14 : 682699.

139. YAN W., SUOMINEN J., SAMSON M. et al. : Involvement of $\mathrm{Bcl}-2$ family proteins in germ cell apoptosis during testicular development in the rat and pro-survival effect of stem cell factor on germ cells in vitro. Mol. Cell. Endocrinol., 2000, 165 : 115-129.

140. ZAMZAMI N., BRENNER C., MARZO I. et al. : Subcellular and submitochondrial mode of action of Bcl-2-like oncoproteins. Oncogene, 1998, $16: 2265-2282$.

141. ZHANG Z.H., HU Z.Y., SONG X.X. et al. : Disrupted expression of intermediate filaments in the testis of rhesus monkey after experimental cryptorchidism. Int. J. Androl., 2004, 27 : 234-239.

142. ZHANG Z.H., JIN X., ZHANG X.S. et al. : Bcl-2 and Bax are involved in experimental cryptorchidism-induced testicular germ cell apoptosis in rhesus monkey. Contraception, 2003, $68: 297-301$.
143. ZHENG S. TURNER T.T., LYZIAK J.J. : Role of Caspase-2 in Germ Apoptosis During the First Phase of Spermatogenesis. Departement of Urology and Cell Biology, University of Virginia Heath Science System, Charlottesville, VA, 2005, Abstract.

144. ZINI A., ABITBOL J., SCHULSINGER D. et al. : Restoration of spermatogenesis after scrotal replacement of experimentally cryptorchid rat testis : assessment of germ cell apoptosis and eNOS expression. Urology, 1999, $53: 223-227$.

145. ZOU H., LI Y., LIU X. et al. : An APAF-1.cytochrome c multimeric complex is a functional apoptosome that activates procaspase-9. J. Biol. Chem., 1999, $274:$ 11549-11556.

Bourse SALF 2004 de Recherche en Andrologie.

Manuscrit reçu : avril 2005 ; accepté juin 2005.

\section{ABSTRACT}

Apoptotic process in testicular germ cells : causes and mechanisms

\section{Souheila AMARA, Aline BOZEC, Mohamed BENAHMED, Claire MAUDUIT}

Spermatogenesis results from a balance between proliferation and apoptosis. An alteration in this balance could lead to testicular diseases such as testicular tumour or infertility. Apoptosis seem to be important in regulating the processes of spermatogenesis since 60 to $75 \%$ of germ cells do not reach the spermatozoa stage. The various molecules of the apoptotic cascade have been detected in rodent or human germ cells, such as effector caspases and upstream proteins from cell death receptor or mitochondrial pathways. One or several different pathways may be involved in the germ cell apoptotic process triggered physiologically, by hormonal deprivation, or by chemical or physical inducers. Finally, caspases appear to play a role in various testicular diseases (particularly infertility).

Key words: spermatogenesis, apoptosis, caspases, $\mathrm{Bc}_{2}$, death receptor pathways, male infertility 